Article

\title{
Complete Chloroplast Genome of Rhipsalis baccifera, the only Cactus with Natural Distribution in the Old World: Genome Rearrangement, Intron Gain and Loss, and Implications for Phylogenetic Studies
}

\author{
Millicent Akinyi Oulo ${ }^{1,2,3,+}$, Jia-Xin Yang ${ }^{1,2,3,+}$, Xiang Dong ${ }^{1,2,3,+}$, Vincent Okelo Wanga ${ }^{1,2,3}$, \\ Elijah Mbandi Mkala 1,2,3 $\mathbb{D}$, Jacinta Ndunge Munyao 1,2,3, Victor Omondi Onjolo 1,2,3, \\ Peninah Cheptoo Rono ${ }^{1,2,3}$, Guang-Wan Hu 1,2,*(D) and Qing-Feng Wang 1,2 ${ }^{\mathbb{D}}$ \\ 1 CAS Key Laboratory of Plant Germplasm Enhancement and Specialty Agriculture, Wuhan Botanical Garden, \\ Chinese Academy of Sciences, Wuhan 430074, China; millicentoulo@gmail.com (M.A.O.); \\ yangjxgz@163.com (J.-X.Y.); directx0831@163.com (X.D.); vincentokelo@gmail.com (V.O.W.); \\ mkala@wbgcas.cn (E.M.M.); jacintandunge.jn@gmail.com (J.N.M.); Onjolovictor@gmail.com (V.O.O.); \\ Peninahrono@yahoo.com (P.C.R.); qfwang@wbgcas.cn (Q.-F.W.) \\ 2 Sino-Africa Joint Research Center, Chinese Academy of Sciences, Wuhan 430074, China \\ 3 University of Chinese Academy of Sciences, Beijing 100049, China \\ * Correspondence: guangwanhu@wbgcas.cn or guangwanhu@sohu.com \\ + These authors contributed equally to this work.
}

Received: 1 July 2020; Accepted: 29 July 2020; Published: 31 July 2020

\begin{abstract}
Rhipsalis baccifera is the only cactus that naturally occurs in both the New World and the Old World, and has thus drawn the attention of most researchers. The complete chloroplast (cp) genome of $R$. baccifera is reported here for the first time. The cp genome of $R$. baccifera has 122, 333 base pairs (bp), with a large single-copy (LSC) region ( $81,459 \mathrm{bp})$, SSC (23,531 bp) and two inverted repeat (IR) regions each $8530 \mathrm{bp}$. The genome contains 110 genes, with 73 protein-coding genes, 31 tRNAs, 4 rRNAs and 2 pseudogenes. Twelve genes have introns, with loss of introns being observed in, rpoc1 clpP and rps12 genes. 49 repeat sequences and 62 simple sequence repeats (SSRs) were found in the genome. Comparative analysis with eight species of the ACPT (Anacampserotaceae, Cactaceae, Portulacaceae, and Talinaceae) clade of the suborder Portulacineae species, showed that $R$. baccifera genome has higher number of rearrangements, with a 19 gene inversion in its LSC region representing the most significant structural change in terms of its size. Inversion of the SSC region seems common in subfamily Cactoideae, and another $6 \mathrm{~kb}$ gene inversion between $r b c L$ - trnM was observed in R. baccifera and Carnegiea gigantea. The IRs of $R$. baccifera are contracted. The phylogenetic analysis among 36 complete chloroplast genomes of Caryophyllales species and two outgroup species supported monophyly of the families of the ACPT clade. $R$. baccifera occupied a basal position of the family Cactaceae clade in the tree. A high number of rearrangements in this cp genome suggests a larger number mutation events in the history of evolution of $R$. baccifera. These results provide important tools for future work on R. baccifera and in the evolutionary studies of the suborder Portulacineae.
\end{abstract}

Keywords: Rhipsalis baccifera; Cactaceae; chloroplast genome; rearrangements; phylogeny

\section{Introduction}

Cactaceae is one of the most conspicuous and diverse angiosperm families of warm arid America [1]. This family is monophyletic [2] and belongs in the suborder Portulacineae of the order Caryophyllales [3]. In this order, family Cactaceae forms a unique clade called ACPT clade together with genus Talinum, 
genus Portulaca and family Anacampseroteae [4]. The basal position of this clade is occupied by genus Talinum which forms the sister group to a subclade consisting of family Anacampseroteae, family Cactaceae, and genus Portulaca. The relationship of the members of this clade, however, remains unclear [4-7]. Family Cactaceae is almost endemic to the New World except for the epiphytic Rhipsalis baccifera (J.S.Muell.) Stearn, which is found naturally occurring in both the New and the Old Worlds [8].

Rhipsalis baccifera (J.S.Muell.) Stearn, commonly known as the mistletoe cactus, belongs to genus Rhipsalis tribe Rhipsalideae of the subfamily Cactoideae [9,10]. This species is morphologically different from its putative terrestrial Cactoideae ancestors, mainly due to the presence of dispersed areoles with minute, bristly spine-like structures (as opposed to large sclerified spines) and its pendulous epiphytic lifestyle in the humid tropics [11]. It being the only cactus species naturally occurring outside the New World [8], has drawn the attention of many scientists. However, despite several theories being proposed to explain the distribution of $R$. baccifera, it is still unclear why it is the only Cactaceae species that occur naturally outside the New World $[1,12,13]$. $R$. baccifera produces soft, small $(5-8 \mathrm{~mm}$ in diameter) globose, sweet and juicy fruit that resemble small grapes, which are fed on by both birds and human beings [14]. It is of medical importance, in that its stem is crushed and used with the juice of Lonchocarpus chrysophyllus Kleinhoonte to treat the bites of coral snakes (Micrurus sp.) and also used together with Philodendron sp. to soothe the wounds of venomous stingrays (Potamotrygon sp.) [15]. Additionally, the whole plant is used as an ingredient in a curative herbal bath [2]. R. baccifera is currently described as having six [9]. The six subspecies include; R. baccifera subsp. horrida (Baker) Barthlott, R. baccifera subsp. baccifera, R. baccifera subsp. erythrocarpa (K. Schumann) Barthlott, R. baccifera subsp. mauritiana (De Candolle) Barthlott, R. baccifera subsp. shaferi (Britton and Rose) Barthlott and N.P. Taylor and R. baccifera subsp. hileiabaiana (J.L. Hage and H.S. Brito) N.P. Taylor and Barthlott [9]. Furthermore, $R$. baccifera has undergone successive polyploidization events and its chromosome number varies from diploid $(2 n=2 x=22)$ to tetraploid $(2 n=4 x=44)$ to octaploid $(2 n=8 x=88)$ [9]. Higher levels of polyploidy are correlated with increased geographic distance from Brazil which is its centre of diversity [16].

Previous studies regarding Rhipsalis baccifera ranged from the quest to understand its distribution [9,12], morphological characters [11,17], and molecular systematics [13,18]. One of the most comprehensive works so far on the evolutionary analysis of $R$. baccifera proposed that this species might have undergone a longer history of evolution in comparison to other cacti but suggested more work to support this idea [19]. Despite the increased attention from researchers, evolutionary history of $R$. baccifera remains unclear. Thus, an analysis of complete chloroplast genome of $R$. baccifera will be of high significance to shed more light on its evolutionary history.

Chloroplast genomes have low evolution rate and maternal inheritance [20] and have thus been found to be ideal in studies of plant phylogeography and molecular evolution, as well as phylogenetic analysis [21-24]. Despite cp genomes of vascular plants being highly conserved in their basic structures and their rates of nucleotide substitutions being generally slow, comparative genomic studies in the past have revealed occasional structural changes, such as inversions, gene or intron losses, and rearrangements among plant lineages [25-28]. Rearrangements in the chloroplast genome were considered to have occurred rarely enough in evolution that they can be used to delineate major groups [29]. Plastid genomes have played a key role in the evolutionary and phylogenetic studies due to their small size and highly conserved gene content and order. Therefore, in this study, we compare the $\mathrm{cp}$ genome of $R$. baccifera to $\mathrm{cp}$ genomes of seven other genomes of the ACPT clade to study their relationship. They include; Talinum paniculatum, Portulaca oleraceae, Carnegieae gigantea, Lophocerus schottii, Mammilaria albiflora, M. solisioides and M. zephyranthoides (the three species of genus Mammillaria represent the three cp genome structures (1-3) respectively found in its members). So far, these are the only available complete $\mathrm{cp}$ genomes of members of this clade, in addition to the other four species of genus Mammillaria previously studied [30] but not mentioned here. Spinacia oleraceae L. was also used in this study as a representative genome of order Caryophyllales. Thus, this study aims at, 
(i) generating the first complete chloroplast analysis study of $R$. baccifera, (ii) conducting complete comparative genomics against other cp genomes of selected members of the ACPT clade of suborder Portulacineae and, (iii) providing insights into the phylogenetic relationships between members of the family Cactaceae, and the ACPT clade.

Incongruences between biological and legal criteria for determining sub specific taxa and the continuing debate among taxonomists regarding the validity of subspecies as a taxonomic unit have resulted in controversies when listing sub species and thus more work is needed to support sub specific nomino [31,32]. Moreover, $R$. baccifera is recorded under its species name both in the Flora of Madagascar and the Flora of Tropical East Africa, though the species have a few differences in their morphology, suggesting non-recognition of the sub specific classification. We therefore choose to retain the species name in our study.

\section{Results}

\subsection{Chloroplast Genome Organization and Features of Rhipsalis baccifera}

The Complete chloroplast genome of $R$. baccifera has a total length of $122,333 \mathrm{bp}$ in size. It displays a typical quadripartite structure with a large single-copy (LSC) region of $81,459 \mathrm{bp}$ in length, separated from the SSC region of 23,531 bp, by two inverted repeat (IR) regions both 8530 bp long (Figure 1, Table 1).

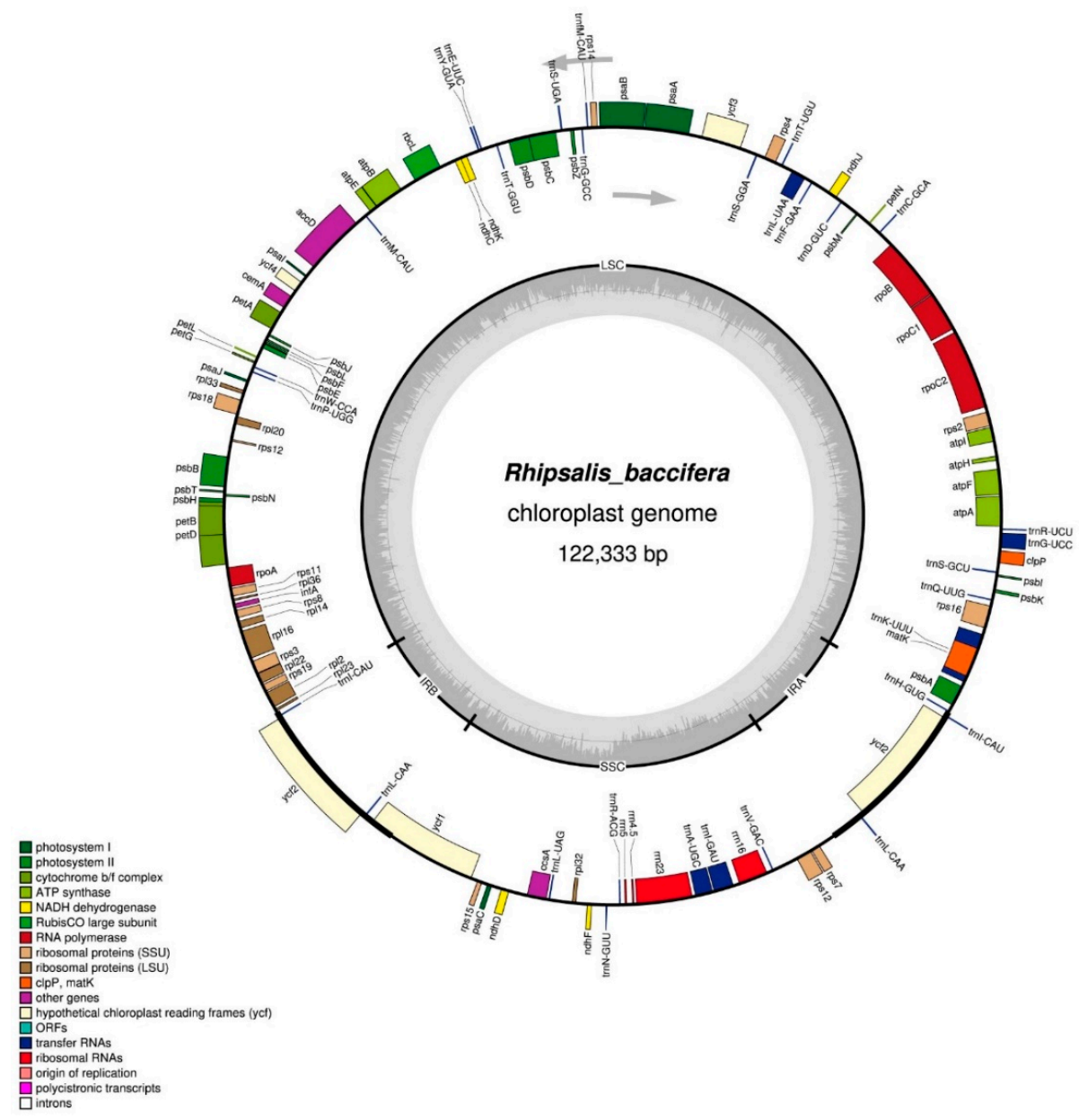

Figure 1. Complete chloroplast genome of Rhipsalis baccifera. Genes belonging to different functional groups are shown in different colors. The arrows in the figure represent the transcription direction of genes. 
Table 1. Chloroplast genome composition of Rhipsalis baccifera.

\begin{tabular}{ccccccc}
\hline Region & Size (bp) & T (U) (\%) & A (\%) & G (\%) & C (\%) & Genes \\
\hline LSC & 81,459 & 32.6 & 31.4 & 17.7 & 18.3 & 84 \\
SSC & 23,531 & 30.5 & 30.2 & 20.3 & 19.0 & 19 \\
IRA & 8530 & 31.4 & 31.7 & 19.0 & 17.9 & 4 \\
IRB & 8530 & 31.4 & 31.7 & 19.0 & 17.9 & 4 \\
Total & 122,333 & 32.1 & 31.2 & 18.3 & 18.4 & 110 \\
\hline
\end{tabular}

The SSC region has higher GC content (39.3\%) compared to the LSC region $(36.0 \%)$ and the IR $(36.9 \%)$ There are 110 unique genes in the cp genome of R. baccifera. Among the 110 genes, 73 are protein-coding genes, $31 t R N A$ genes and four $r R N A$ genes (Figure 1; Table 1). Two pseudogenes, i.e., $y c f 1$ and $r p l 23$, were detected in the $\mathrm{cp}$ genome of $R$. baccifera. A total of 12 genes have introns, with ycf3 having two introns and the others (trnI-GAU, trnA-UGC, trnL-UAA, trnG-UCC, trnK-UUU, $r p L 16, p e t B, p e t D, r p s 12, a t p F, r p s 16)$ having one intron. The $r p s 12$ gene is transplicated but unlike in the chloroplast genomes of most species with three exons, where the first exon is located in the LSC region, while the other two exons are duplicated in IR regions, in R. baccifera cp genome, rps12 gene has two exons with the first exon located in the LSC and the second exon in the SSC region. Pseudogenization of genes has also been observed in rpl23 and ycf1. Additionally, the $n d h D$ gene is a pseudogene in Carnegiea gigantea, Lophocereus schottii and genus Mammillaria, while this is not the case in R. baccifera and T. paniculatum. Additionally, the ndhJ gene, which might have been lost in the chloroplast genomes of the so far analyzed Cactaceae species, i.e., Lophocereus schottii, Carnegiea gigantea and in members of genus Mammillaria, was discovered in the chloroplast genome of $R$. baccifera. It is found located between trnD-GUC and trnF-GAA. However, this gene also exists in the cp genomes of Talinum paniculatum and Portulaca oleracea, two members of this suborder Portulacineae, though at a different location; between gene $n d h K$ and trnF-GAA.

Furthermore, the $\mathrm{cp}$ genome of $R$. baccifera displayed additional features that were absent in the $\mathrm{cp}$ genomes of other cacti, but present in the $\mathrm{cp}$ genomes of Talinum paniculatum and Portulaca oleracea. $R$. baccifera might have gained introns or maybe retained them in some genes. The pet $B$ gene in R. baccifera cp genome for example, has an intron as is the case in Portulaca oleracea and T. paniculatum, whereas this gene lacks introns in most cp genome of members of Cactaceae family so far studied.

\subsection{Inversions and Rearrangements in the cp Genome of Rhipsalis baccifera}

\subsection{1. $r b c L-a t p B-a t p E-t r n M$ Inversion}

The gene order in the ancestral large single copy (LSC) region has been partially retained in the $\mathrm{cp}$ genome of $R$. baccifera from the ideal order across angiosperms with some few inversions observed; for example, a small $\sim 6 \mathrm{~kb}$ inversion involving four genes: $r b c L$ - atpB - atpE-trnM (Figure 2). R. baccifera and $C$. giganteae have lost the $\operatorname{trn} V$ gene. 


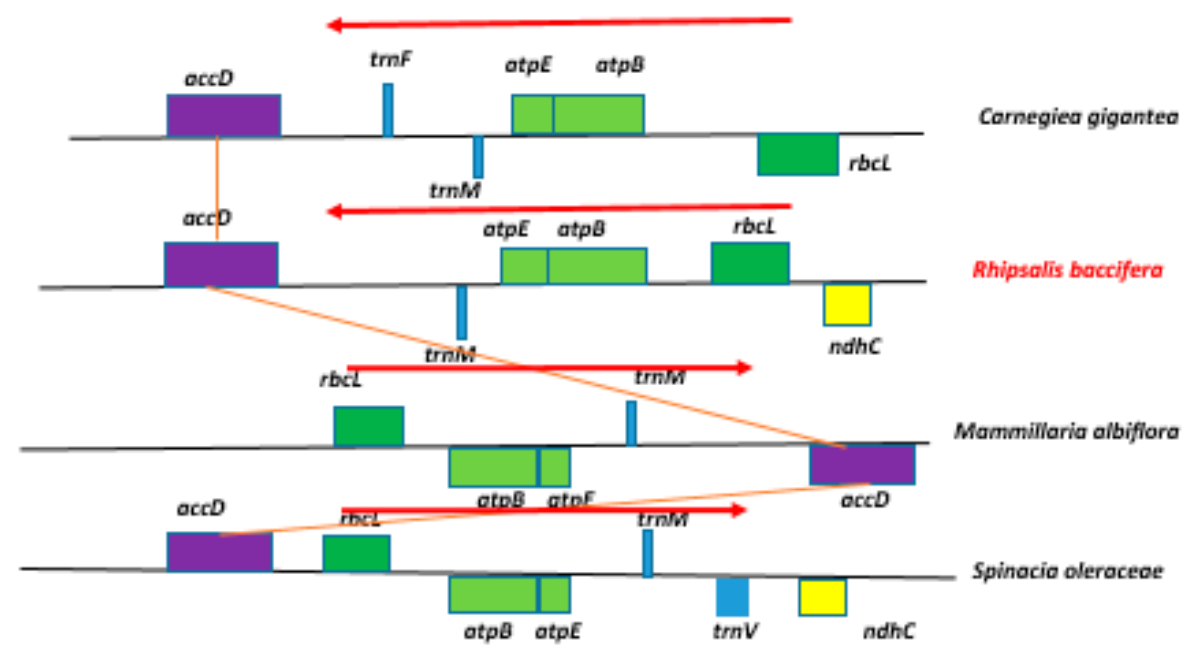

Figure 2. Structural organization of a portion of the LSC region showing location of the $\sim 6 \mathrm{~kb}$ inversion in the cp genome of R. baccifera and other species of suborder Portulacinae relative to Spinacia oleraceae cp genome. Talinum paniculatum and Portulaca oleraceae have similar arrangement of these genes as in S. oleraceae.

\subsubsection{A 19-Gene Inversion in the LSC of Rhipsalis baccifera}

The LSC region of R. baccifera also displays a large inversion of 19 genes (Figure 3). The region occupied by genes ndhJ-trnF-trnL-trnT-rps4-trnS-ycf3-psaA-psaB-rps14-trnfM-trnG-psbZ-trnS-psbC$p s b D$-trnT-trnE-trnY in the chloroplast genome of $R$. baccifera has been inverted. R. baccifera cp genome was only compared to that of $S$. oleraceae which is a representative genome of order Caryophyllales since this inversion has not been previously observed in other Caryophyllales so far studied.

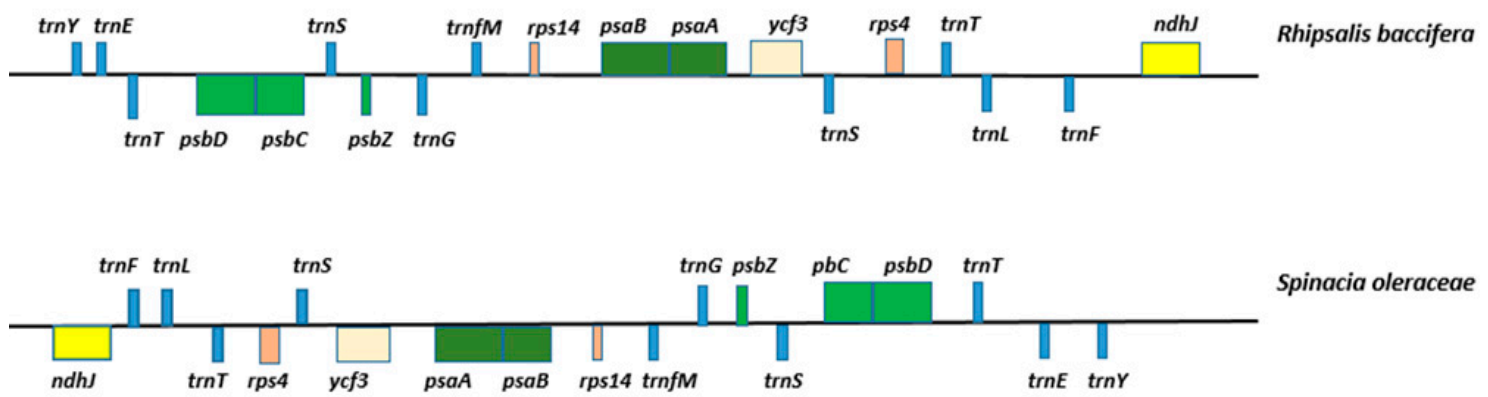

Figure 3. Structural alignment of the LSC region between genes ndhJ- trnY. Figure showing inversion in the cp genome of $R$. baccifera relative to Spinacia oleraceae.

\subsubsection{Rearrangements in the SSC Region}

The IR region of the $R$. baccifera cp genome is significantly contracted and hence some genes that are ideally located in the IR regions of most angiosperms cp genomes have been moved to the SSC region (Figure 1). Moreover, we observed an inversion of the SSC region of the chloroplast genome of R. baccifera compared to the structure of other $\mathrm{cp}$ genomes (Figure 4). We compared R. baccifera to T. paniculatum since C. gigantea has lost its IRs, and most species of genus Mammillaria except M. zephyranthoides have IRs that are highly contracted. The arrangement of these genes is similar in T. paniculatum and P. oleraceae, which are similar to that of most angiosperms. 


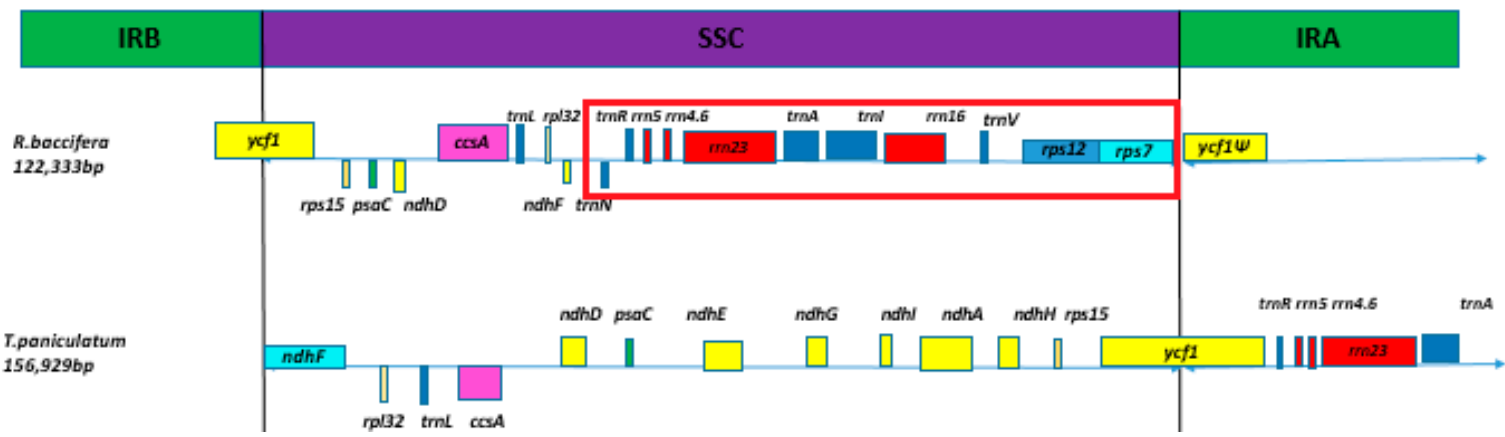

Figure 4. Structural comparison of the SSC region of R. baccifera to Talinum paniculatum, displaying the SSC inversion in R. baccifera. A display of the SSC inversion in R. baccifera.

\subsection{Amino Acid Composition of Coded Proteins in R. baccifera cp Genome}

According to the analysis of codon usage in this study, 20,555 codons are involved in coding of 73 protein genes and 31 tRNA genes in the cp genome of Rhipsalis baccifera. Leucine $(10.14 \%)$ and Isoleucine $(7.88 \%)$ were the most frequently used amino acids, while codons for cysteine $(1.08 \%)$, represented the least prevalent amino acids (Figure 5a. This has been also observed for other members of Cactaceae family analyzed in this study. UAA was also observed to be the most frequently used stop codon in R. baccifera (Table S2). Codon usage in the suborder Portulacineae is generally conserved, with no significant variation (Figure $5 b$ ).

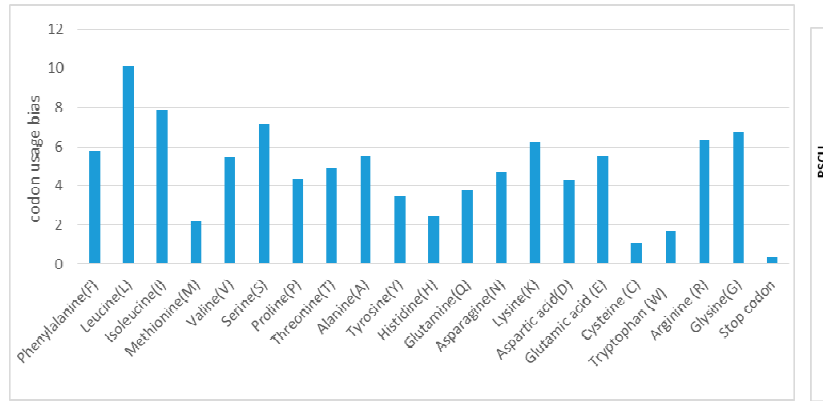

(a)

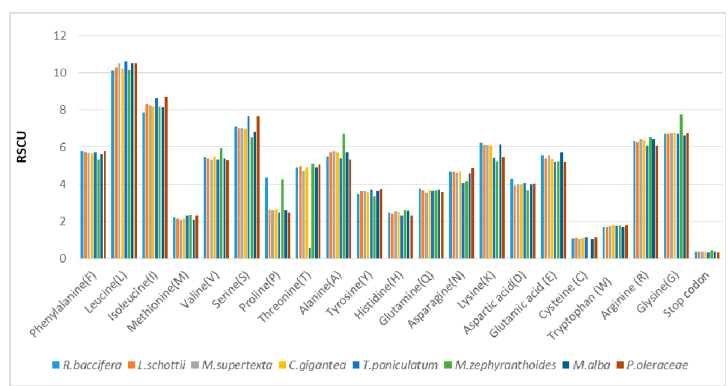

(b)

Figure 5. Amino acid composition of proteins coded by the chloroplast genome of R. baccifera (a) and members of the Portulacineae (b).

\subsection{Repeats}

A total of 49 repeat sequences were identified using REPuter software. Out of which, 33 were forward repeats and 16 were palindromic repeats. No complement and reverse repeats were found in the chloroplast genome of $R$. baccifera. The repeats ranged from 46 to $122 \mathrm{bp}$ in length. The majority were located in the intergenic spacer (IGS) and intron sequences. Twenty repeats are located in exons of rps7, rps19, rps18, accD, clpP and ycf1 (Table S3).

Another type of repeat sequence found in chloroplast genomes is the simple sequence repeats (SSRs), also called microsatellites. In the cp genome of R. baccifera, there are 62 SSRs, with the highest number being of mononucleotide repeats (38). There were also 9 dinucleotide repeats, 5 trinucleotide repeats, 8 Penta nucleotide repeats, and 2 hexanucleotide repeats (Figure 6a). Compared to other members of suborder Portulacineae, Portulaca oleraceae had the highest number of SSRs (111), while Carnegiea gigantea had the least (43) (Figure 6b) (S4). 


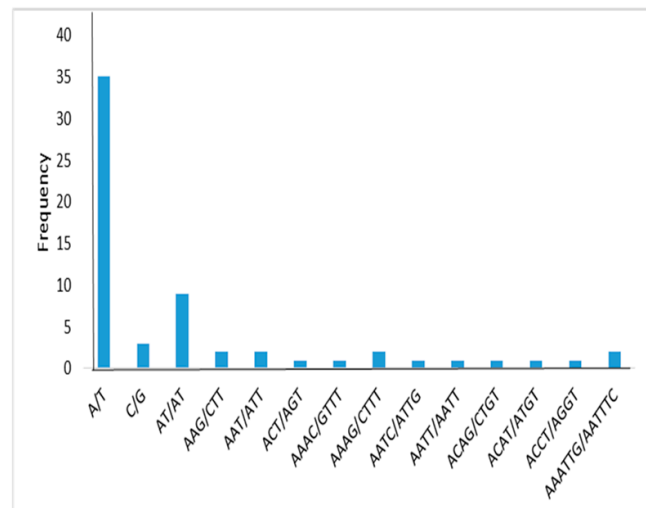

(a)

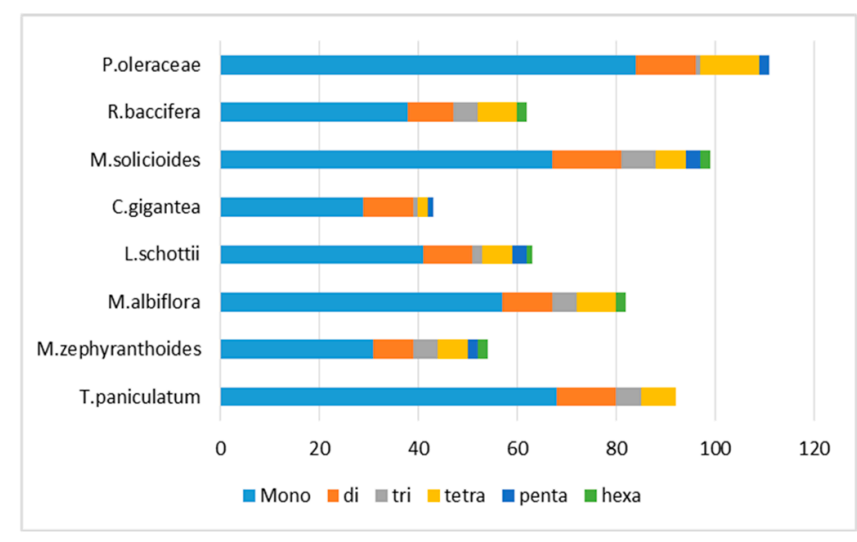

(b)

Figure 6. Simple sequence repeats (SSRs) type, distribution, and presence in suborder Portulacineae; (a) Number of detected SSR motifs in different repeat types in R.baccifera chloroplast genome. (b) Number of identified repeat sequences in eight chloroplast genomes.

\subsection{Boundaries between IRs and the Single Copy Regions}

The contraction or expansion of the IR regions varies in the cp genomes of various plants. In this study, we analyzed the IR contraction and expansion of the $R$. baccifera $\mathrm{cp}$ genome by comparing the IR-LSC and IR-SSC borders with those of four other species of suborder Portulacineae. For the family Cactaceae Mammillaria solisioides was randomly selected to represent the genus Mammillaria, whereas Carnegiea gigantea, though having lost one of its IR regions, was also used as in [33]. Among them, Talinum paniculatum had the longest chloroplast genome, while $C$. gigantea had the shortest. Rearrangement was observed in the SSC region of family Cactaceae. In M. solisioides, ycf2 stretches out of the IR region due to the expansion of the IR and rearrangement within its cp genome. The IR region of $R$. baccifera was observed to be highly contracted, resulting in the pseudogene of rps 23 being located in the LSC region instead of the IR. ycf1 gene in R. baccifera is s pseudogenized (Figure 7).

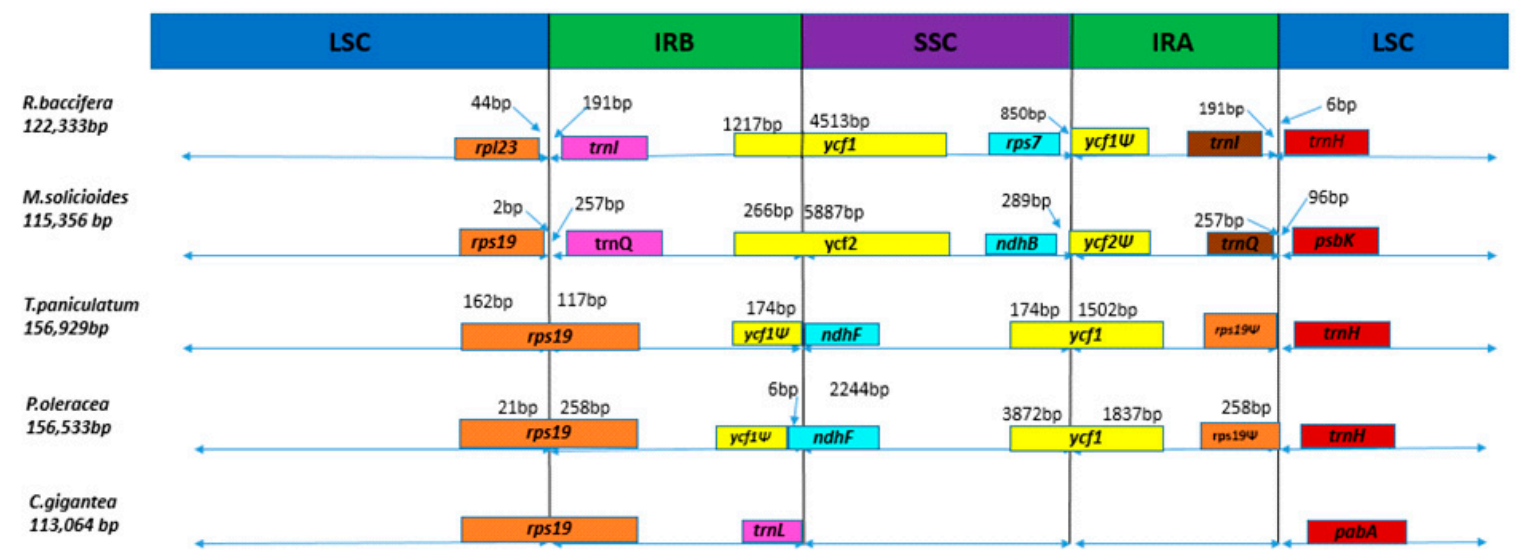

Figure 7. IR borders of the suborder Portulacineae species. Boundaries of the LSC-IRB and the SSC-IRA regions in suborder Portulacineae species. Genes with the symbol $\Psi$ are pseudogenes.

\subsection{Genome Comparison and Sequence Divergence}

The overall sequence identity of the complete $\mathrm{cp}$ genome sequences of eight species of suborder Portulacineae, including $R$. baccifera was comparatively analyzed using MVISTA software with annotation of $R$. baccifera as the reference (Figure 8). The results show that the sequences vary in length with Talinum paniculatum being the longest (156,929 bp), and Mammillaria zephyranthoides the shortest (107,343 bp). Compared to the non-coding regions, the coding regions seemed more conserved. 
The LSC regions are generally least conserved among these species of suborder Portulacineae with notable divergences in some genes such as $r p s 16, a c c D, n d h J$ and $n d h K$.

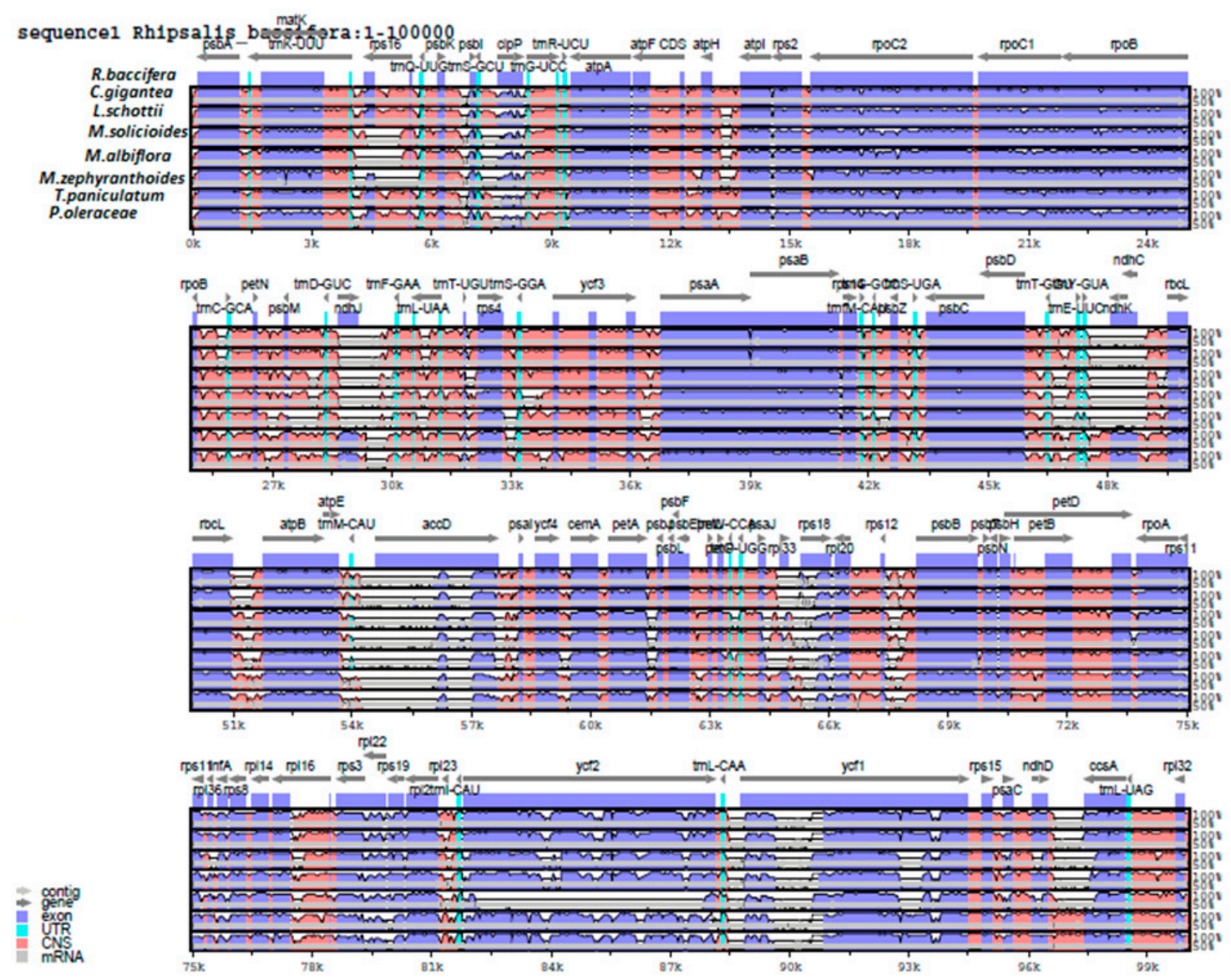

Figure 8. Sequence alignment of eight $\mathrm{cp}$ genomes of the suborder Portulacineae using mVISTA program, with the annotation of $R$. baccifera as a reference. The top line shows genes in order (transcriptional direction indicated with arrow). A cut-off of $70 \%$ identity was used for the plots, and the Y-scale represents the percent identity between $50-100 \%$. Genome regions are color coded as exon, intron, and conserved non-coding sequences (CNS).

MAUVE graphic of the structural alignments of complete chloroplast genomes of these species also revealed divergences. We first compared species of family Cactaceae (Figure 9), where a unique inversion and rearrangement was observed only in R. baccifera at the LSC region from gene $p s a I-t r n Y$ which is flipped in the opposite direction compared to their arrangements in the cp genomes of the other species. When compared to other species of suborder Portulacineae (Figure S1), this rearrangement was still only unique to $R$. baccifera. Inversions previously observed in the LSC region $R$. baccifera are also evident in the structural alignment.

Moreover, in genus Mammillaria, an inversion and rearrangement were observed in the LSC at the region between genes trnM-CAU and trnE-UUC (highlighted in red). In addition, there is a rearrangement in the cp genome structure of $M$. zephyranthoides (circled) (Figure 9) below. 


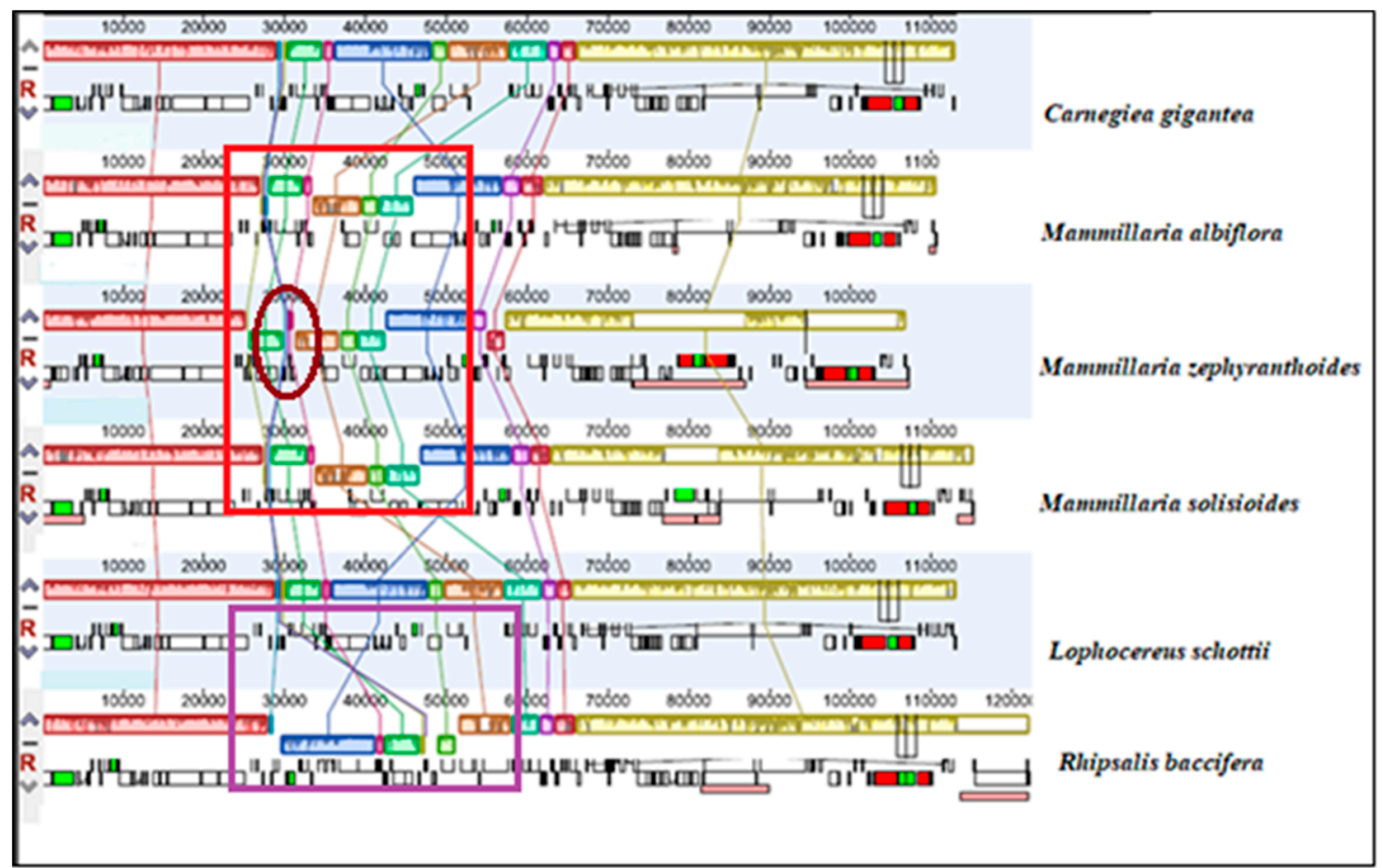

Figure 9. Genome structural alignment map of six chloroplast genomes of species in family Cactaceae, with Rhipsalis baccifera as the reference species aligned using MAUVE software. Local collinear blocks within each alignment are represented as blocks of similar color connected with lines. Annotations of $r R N A$, protein coding and $t R N A$ genes are shown in red, white, and green boxes, respectively.

\subsection{Phylogenetic Analysis}

The phylogenetic analysis involved 36 species of order Caryophyllales and two outgroups. The species of suborder Portulacineae form a clade supported by strong bootstrap values, within which a clade of family Cactaceae is displayed (Figure 10). Interestingly, $R$. baccifera forms a branch occupying a basal position in the clade formed by Cactaceae species. This can be used in future studies of this species to understand its relationship to other Cacti and its natural occurrence outside the New world (Table S1) (Figure 10). 


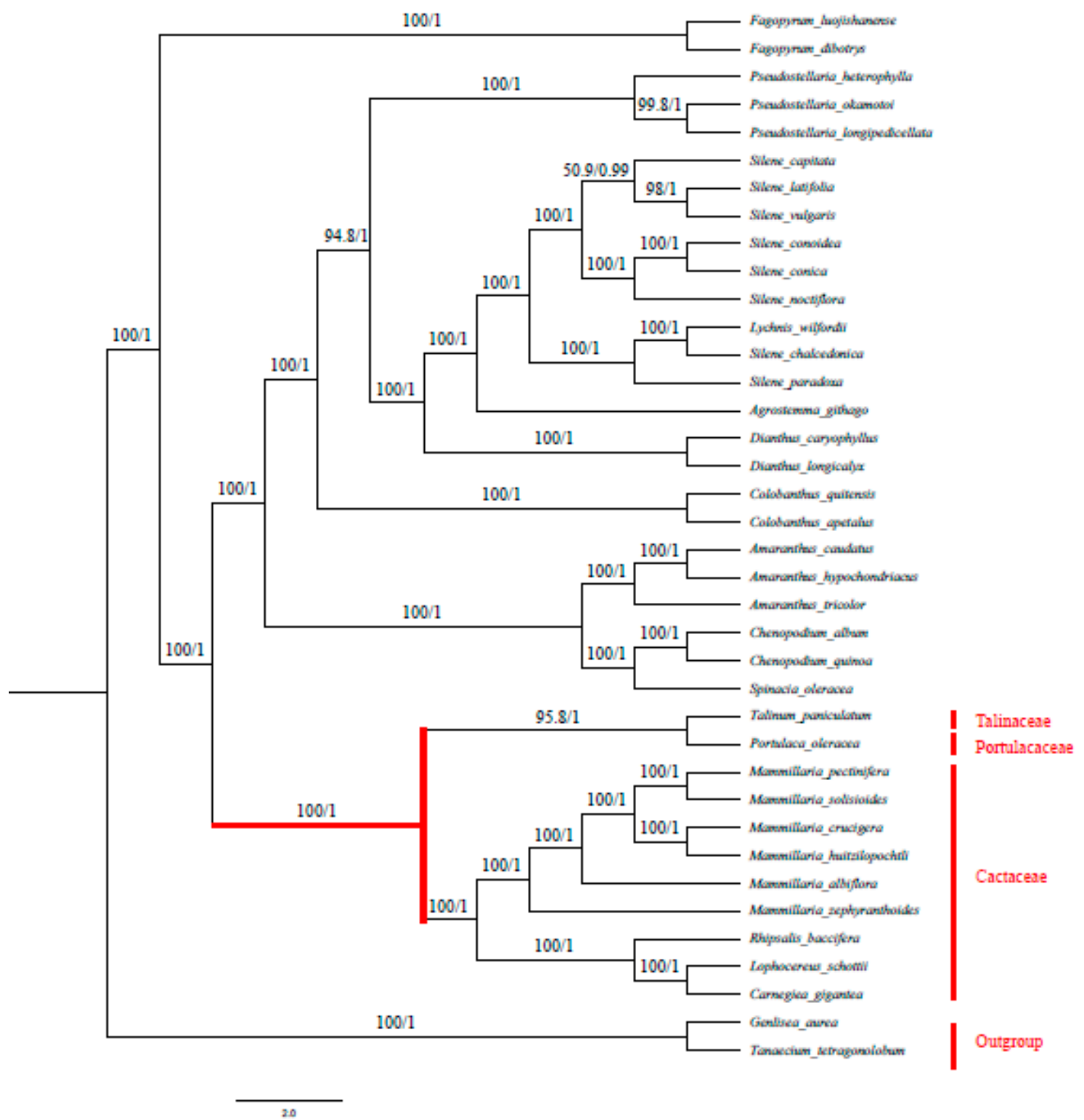

Figure 10. Combined phylogenetic tree of 36 species order Caryophyllales using maximum likelihood (ML) and Bayesian methods based on their complete chloroplast genomes. Two outgroups from order Lamiales were used. The numbers above the nodes are support values with ML bootstrap values on the left and Bayesian posterior probabilities values on the right.

\section{Discussion}

\subsection{Chloroplast Genome Organization and Features of Rhipsalis baccifera}

The chloroplast genome of $R$. baccifera displays a typical angiosperm cp genome structure [34] of a quadripartite organization consisting of two copies of inverted repeats (IRs), a large single copy (LSC) region and a small single copy region. However, this cp genome also displays some features that are uncommon in other cp genome structures.

The inverted repeat regions (IRs) are contracted and have consequentially resulted in some typical IR region genes to be located in the LSC and SSC regions. IR contraction has been previously observed in other species and described to be as a result of evolution $[35,36]$. Some genes in R. baccifera also displayed some interesting features. Loss of introns for example, was observed in some genes. The rps12 gene in this cp genome has lost one intron. This loss of the rps12 3'end intron has also 
been observed in Aspagarales [37] and is described to be as a result of convergent evolution. The loss of an intron of rps12 gene has also previously been observed in legumes [38] and in some parasitic plants such as Cuscuta [39]. However, in comparison to other species of the suborder Portulacineae, Mammillaria zephyranthoides, Talinum paniculatum and Portulaca oleraceae displayed the common 3 exons feature of the rps12 gene, while other members of genus Mammillaria had three exons of the rps12 gene but two exons are in the LSC region and one in the SSC, and this may be due to the IR contraction observed in these species $[30,33,40]$. Carnegiea gigantea, despite losing its IRs, also still retains three exons of the rps12 gene, by displaying a three-part structure: two copies of $5^{\prime}$ exon in inverted orientation and one copy of $3^{\prime}$ exon [41]. rps12 gene is generally highly conserved and changes in its structure have been previously suggested to be a result of evolution [42,43]. The loss of introns in the $\operatorname{clpP}$ gene and has only been observed in the cp genome of $R$. baccifera among all species of suborder Portulacineae studied here. However, this has previously been observed in the chloroplast genomes of some species of order Caryophyllales, specifically in tribe Sileneae [44,45]. Interestingly, according to a previous study, the inversion of $\operatorname{trn} Y$-psaI region is always coupled with the loss of introns in the clpP gene, which has also been observed in R. baccifera. This feature has been found in the species of tribe Sileneae that display the same unusual trait in their cp genomes e.g., Silene chalcedonica and S. notiflora [45]. Assuming this is not ancestral, as it is not found in the most common chloroplast genomes of Caryophyllales, this thus indicates that R.baccifera has undergone a number unusual changes in the course of its evolution, which though uncommon, are similar to those in some species of tribe Sileneae. The loss of both $c l p P$ gene and $r p s 12$ gene in the same chloroplast genome was first observed in, Cicer arietinum [38] and was described as unique. The petB gene in $R$. baccifera cp genome has an intron as is the case in P. oleracea and T. paniculatum, whereas this gene lacks introns in most cp genome of members of Cactaceae family so far studied, but was observed in a recent study to be present in Opuntia quimilo [46]. Assuming R. baccifera has gained the petB gene intron, then R. baccifera might have gained this intron during its evolution to enhance the expression level of this pet $B$ gene. Introns are important in the regulation of gene expression. They can enhance the gene expression level, on the special position, in the specific time [24].

Additionally, the contraction of the IR region led to the pseudogenization of the rpl23 gene and its position in the LSC region of $R$. baccifera cp genome unlike in other angiosperms where it is found in the IRs.

The $n d h J$ gene is important for the stability of the activities of NDH-1 complexes that are essential components in PSI cyclic electron flow during photosynthesis [47]. The gene, which might have been lost in the chloroplast genomes of the so far analyzed Cactaceae species i.e., L. schottii, C. gigantea and in members of genus Mammillaria [40,41], was discovered in the chloroplast genome of $R$. baccifera. It is located between $\operatorname{trnD-GUC}$ and $\operatorname{trnF-GAA}$. The existence of $n d h J$ gene has also been observed in the cp genomes of other Caryophyllales, e.g., in some members of suborder Portulacineae [33,40], though at differing locations. For instance in T. paniculatum and P. oleracea, two members of this suborder, the gene is found between $n d h K$ and $t r n F-G A A$. The difference in location is probably because of the inversion in the LSC region of $R$. baccifera affecting genes $n d h J-t r n Y$.

Gene pseudogenization is observed to differ in these genomes. The ycf1 gene for example, is pseudogenized in the cp genome of $R$. baccifera, while this is not the case in other previously studied Cacti $[30,41]$. Additionally, the $n d h D$ gene is a pseudogene in C. gigantea, L. schottii and genus Mammillaria, while this is not the case in R. baccifera and T. paniculatum. The rpl23 in R. baccifera is a pseudogene as in other cacti, but unlike other members of family Cactaceae, where it is located in the IR region e.g., in genus Mammillaria [30], for the case of $R$. baccifera, this pseudogene is found in the LSC region and this might be as a result of IR contraction in its cp genome.

\subsection{Inversions and Rearrangements in the cp Genome of Rhipsalis baccifera}

The structure of the R. baccifera cp genome also displays several inversions, gene losses, and transpositions in the LSC region. There is a small $\sim 6 \mathrm{~kb}$ inversion involving four genes: $r b c L$ - 
atpB - atpE-trnM (Figure 2). This has also been previously observed in Carnegiea gigantea [41] and other Caryophyllales such as Atriplex hastata, Chenopodium murale and Pereskia grandiflora and in Lychnis wilfordii [44,48], though as in Carnegiea gigantea, this inversion also led to the loss of $\operatorname{trn} V$ gene in $R$. baccifera. However, in all these other species, this inversion seems to have occurred once, but in $R$. baccifera cp genome, the $r b c L$ gene seems to have been inverted again. Though the inversion of the $r b c L-a t p B-a t p E-t r n M$ region seems to be a common feature among members of order Caryophyllales, the second time inversion of the $r b c L$ gene seems to be unique to only $R$. baccifera. We suppose that this might be because $R$. baccifera might have undergone more mutational events during its evolution. However, more work should be done to clarify this.

A larger inversion was additionally observed in the LSC region of Rhipsalis baccifera that constituted an inversion of 19 genes. The LSC region occupied by genes ndhJ-trnF-trnL-trnT-rps4-trnSycf3-psaA-psaB-rps14-trnfM-trnG-psbZ-trnS-psbC-psbD-trnT-trnE-trnY in the chloroplast genome of R. baccifera has been inverted and this has not been observed in other Cactaceae species or suborder Portulacineae species previously studied. However, similar inversions have been partially observed in two other species of the order Caryophyllales; Silene noctiflora and Mammillaria zephyranthoides. S. noctiflora was previously described as having the most complicated structure of the cp genome in order Caryophyllales due to a high number of inversions, rearrangements and transpositions that also occurred in this region for genes $p s b D-a c c D$, petL-clpP, trnD-T and $p s a I-p s b E$ [45]. In M. zephyranthoides, the LSC region seems to have undergone several inversions and transpositions too [30]. The inversions and transposition events seem to have occurred several times and we suggest that first, there was an inversion and transposition of the region psal-pet $A$, then the transposition of the $\operatorname{acc} D-\operatorname{trn} M$, followed by another inversion of $a c c D$ gene, and later the $r b c L-t r n M$ inversion. However, the inversions at the LSC region of $R$. baccifera seems to have been larger compared to $M$. zephyranthoides. Our study therefore provides important insights for future studies on the relationship between these species.

Moreover, we observed another inversion of the SSC region of $R$. baccifera chloroplast genome in comparison to the structure of most angiosperms' cp genomes. This was also observed in the cp genome of $C$. gigantea and M. solisioides but was not the case in Opuntia as in a recent study of O. quimilo [46]. We suggest that this might be a unique feature of subfamily Cactoideae.

\subsection{Amino Acid Composition of Coded Proteins in R. baccifera}

The genetic codes of different organisms are often biased toward using one of the several codons that encode the same amino acid over others [49]. Changes in the codon usage tend to reflect the evolution of chloroplasts [50], and thus might provide insight on the evolutionary history is a measure of non-uniform synonymous codon usage in coding sequences. It is the ratio between frequency of use and expected frequency of a particular codon. Relative synonymous codon usage (RSCU) values $<1.00$ indicate use of a codon less frequent than expected, while codons used more frequently than expected have a score of $>1.00$ [51].

This study concluded that the total number of codons that are involved in protein coding in the $\mathrm{cp}$ genome of $R$. baccifera is 20,555 codons describing the coding capacity of the 73 protein-coding genes and 31 tRNA genes of $R$. baccifera chloroplast genome. Codon usage in the suborder Portulacineae is generally conserved, with low variation.

\subsection{Repeats}

Repeat sequences provide important information about genomes. The highly rearranged plastomes contain a high frequency of large repeats [52], some of which represent full or partial duplications of genes. Repetitive DNA in the chloroplast genome of $R$. baccifera may be associated with the elongations of protein-coding genes and pseudogenes (e.g., rps23, ycf1, and rps19), tRNA genes (e.g., trnL-CAA and trnfM-CAU), and intergenic spacers of both single copy and IR regions. R. baccifera has a higher frequency of large repeats among these species and thus also the most rearranged. The exon of the $a c c D$ gene has a high frequency of repeats that range between $48-82 \mathrm{bp}$, which we hereby suggest as a 
result of gene elongation as also witnessed by the larger size of this gene in $R$. baccifera cp genome in comparison to other Portulacineae cp genomes. This is also the case in the rps18 gene of this genome which we also assume might have undergone gene elongation.

Microsatellites are tandem repetitive DNA sequences, comprising of one to six (mono-, di-, tri-, tetra-, penta-, and hexa-) repeat nucleotide units. Their highly polymorphic nature makes them important molecular markers in plant systematics, in mapping genomes, in population structure and evolutionary processes, taxonomic studies among others [53]. In the cp genome of $R$. baccifera, there are 62 SSRs; with the highest number being of mononucleotide repeats (38) (Figure 6b). Mononucleotide SSRs were the most abundant repeats in all species, with $\mathrm{A} / \mathrm{T}$ mononucleotide repeats being the most frequent SSRs. This result is consistent with previous studies that $\mathrm{A} / \mathrm{T}$ repeats are the most abundant SSRs in the cp genomes [33]. These identified repeats can be useful in future population genetics and phylogenetic studies involving $R$. baccifera.

\subsection{Boundaries between IRs and the Single Copy Regions}

Changes in the IR region such as expansion, contraction or even loss are one of the common types of gene order rearrangement types that occur in the chloroplast genomes, and are presumed to might have happened during genome evolution. For example, both the loss of one copy of the IR and inversions are extremely useful characters in legume phylogeny [54,55], defining large clades within the family.

In the chloroplast genome of R. baccifera, the boundaries of the IR and Single Copy (SC) regions suggest a contraction of the IR regions of $R$. baccifera cp genome. Compared to the typical structure of the IR region in the cp genome of tobacco, the typical angiosperm cp genome structure [56], the IR regions in $R$. baccifera have been contracted resulting in the displacement of most usually IR-located genes to the SC regions. This has also resulted in the loss of a copy of RNA genes that are normally duplicated in the IRs as seen in Figure 7. The contraction of the IR as explained before, has resulted in a high number of repeats in the IR regions and the intergenic spacer regions found in the IR borders. IR contraction observed in the $\mathrm{cp}$ genome of $R$. baccifera might be a result of rearrangements and structural changes that occurred during its genome evolution. R. baccifera might have also lost the PPR4 (pentatricopeptide repeat (PPR), which is a degenerate 35-amino acid repeat motif that is widely distributed among eukaryotes) which is associated in vivo with rps12-intron 1 and is also required for its splicing [57].

\subsection{Genome Comparison and Sequence Divergence}

MVISTA analysis reveals that LSC regions are generally least conserved in suborder Portulacineae with notable divergences in some genes such as $r p s 16, a c c D, n d h J$ and $n d h K$. The accD gene in $R$. baccifera is the largest in size (3072 bp) in all the analyzed representatives of suborder Portulacineae herein. It is also pseudogenized in all other species of family Cactaceae analyzed herein. High divergence was observed in genes $n d h K, n d h J$ and rps16. Genes $n d h K$ and $n d h J$ are absent in the chloroplast genomes of the so far analyzed Cactaceae species except in $R$. baccifera, while the gene rps16 is pseudogenized in genus Mammillaria. The pseudogenization of the rps16 gene has also been observed in other studies and has been assumed to be as a result of the dual targeting of the nuclear rps16 copy to the plastid and mitochondria, signifying that the chloroplast-encoded rps16 gene, which is important for plant survival, has been functionally replaced by a nuclear gene that can encode both mitochondrial and chloroplast thus the chloroplast gene rps16 has been silenced and has become a pseudogene and its function replaced by the nuclear-encoded rps16 [58]. The clpP gene in R.baccifera has also lost introns. The ycf2 gene is also pseudogenized in M. zephyranthoides and reduced in size unlike in other species of Portulacineae.

Moreover, the comparative analysis using MAUVE reveals inversions in $R$. baccifera, in the LSC regions; (1) rbcL-trnM and (2) ndhJ-trnY (which might be the unique feature of this genome) and (3) a transposition and loss of introns of gene $\operatorname{clpP}$ and (4) loss of one intron of rps12 gene. M. zephyranthoides 
has two rearrangements in addition those observed in other species of this genus i.e., (1) region between genes rps18-trnW and (2) psbZ-trnT genes. We therefore conclude that these multiple inversions, intron loss and rearrangements observed in these species is as a result of parallel evolution in this order, and we agree with previous studies which suggested that there is a correlation between gene rearrangements, and changes in the genome structure of a chloroplast genome of a species and evolution [52].

\subsection{Phylogenetic Analysis}

The combined Bayesian/maximum likelihood tree showed that $R$. baccifera formed a subclade from other members of family Cactaceae, which occupied a basal position of the family Cactaceae clade in the tree, with strong support values. Chloroplast genome rearrangements have been previously described as mutational events [29] and we thus propose that this species might have undergone a larger number of mutational events during its evolution in comparison to other species of family Cactaceae. We also suggest that these structural changes in the cp genome of $R$. baccifera might have occurred after $R$. baccifera had diverged from other cacti, which could explain the basal position of this species when phylogeny is inferred based on chloroplast sequences.

Therefore, in regard to the explanation of the unique distribution of $R$. baccifera, our study rules out the proposed idea of $R$. baccifera being a primitive member of family Cactaceae and we support the idea of bird dispersal proposed by Barthlott [12] and further redefined by Korotkova [19] as having occurred several times to and from the New and Old Worlds.

The members of the ACPT clade herein also form a common clade. The relationship between the members of this clade has been previously described as unclear [4]. However, few studies have been done using chloroplast DNA to analyze their relationship. This study involves the use of complete chloroplast genomes to analyze their phylogenetic relationship, and though not all representatives were available in our analyses, Figure 10, suggests a close relationship between Talinum paniculatum and Portulaca oleraceae as suggested by previous studies $[7,59,60]$, therefore differing from conclusions of previous studies [33]. We hereby suggest that more work should be done on the phylogenetic analysis of these species using their complete chloroplast genomes.

\section{Materials and Methods}

\subsection{Chloroplast Genome Sequencing and Assembly}

Fresh Rhipsalis baccifera leaves were collected from Kasigau forest in Taita $\left(03^{\circ} 50^{\prime} \mathrm{S}, 38^{\circ} 39^{\prime} \mathrm{E}\right.$, Alt. $800 \mathrm{~m}$ ), Kenya, and fast dried in silica gel for DNA extraction. The dried leaves and voucher specimens were later stored at the East Africa Herbarium, National Museums of Kenya (EA) and the Herbarium of Wuhan Botanical Garden (HIB) (Voucher Number: SAJIT- 3421). The genomic DNA was extracted from about 100 micrograms of the leaves using a modified cetyltrimethylammonium bromide (CTAB) method as described by Doyle [61].

The genome was sequenced using the Illumina platform at Novo gene Company (Beijing, China). The low quality data and adaptors were later filtered, and the obtained clean data was assembled using GetOrganelle-1.6.2 software [62], with Arabidopsis thaliana as the reference genome. The assembled genome was then manually corrected. We used Bandage software to check these results of the assembled genome and we then selected an optimal result. Later, the large reverse areas in these results, were manually adjusted. Finally, Geneious Prime 2019.2.1 (https://www.geneious.com) was used to determine the inverted repeat regions.

\subsection{Genome Annotation and Codon Usage Analysis}

GeSeq online tool was then used to annotate the assembled chloroplast genome with default settings [63]. Annotations of $t R N A s$ were confirmed using the tRNAscan-SE [64]. The validation of the cp genome of R. baccifera was then done using a standalone command line annotation tool called PGA (Plastid Genome Annotator) [65]. The gene map of the complete cp genome was drawn 
using OrganellarGenome DRAW software [66] (Figure 1). The annotated cp genome was submitted to GenBank (GenBank number: MT821847).

MEGA v.7.0 [67] was used to analyze the characteristics of the variations in synonymous codon usage, the relative synonymous codon usage values (RSCU), codon usage, and the GC content.

\subsection{Repeat Structure and Single Sequence Repeats (SSRs) Analysis}

REPuter [68] was used to visualize the various types of repeats in the Rhipsalis baccifera cp genome (forward, palindrome, reverse, and complement sequences) with a minimum repeat size of $30 \mathrm{bp}$ and sequence identity of no less than $90 \%$ (hamming distance equal to 3). Simple sequence repeats (SSRs) were identified using the software MISA [69] with the following minimum number of repeats: 10 for mono, 5 for di-, 4 for tri-, and 3 for tetra-, 3 for penta, and 3 for hexa-nucleotide SSRs.

\subsection{Genome Comparison and Sequence Divergence}

Comparison of whole chloroplast genomes of eight species, which include; Talinum paniculatum, Portulaca oleraceae, Carnegieae gigantea, Lophocerus schottii, Mammilaria albiflora, M. solisioides and M. zephyranthoides (the three species of genus Mammillaria represent the cp genome structure of the three structures (1-3) respectively found in its members) was performed and visualized using mVISTA software [70] with the annotation of Rhipsalis baccifera as a reference. MAUVE v1.1.1 software [71] was used with its default settings to perform structural genomic sequence alignment of the complete genomes, to study, and analyze structural changes, gene order, and rearrangements.

\subsection{Phylogenetic Analysis}

Analysis of the phylogenetic relationships and placement of species of suborder Portulacineae was done using complete chloroplast genome sequences. We downloaded 36 previously sequenced members of order Caryophyllales and two additional outgroups from order Lamiales, from the NCBI database (Table S1) for analysis. Multiple sequence alignment of the 38 complete cp genome sequences was done using MAFFT with default parameters. Model Finder program [72] integrated in phylosuite was used to select the best fit model. GTR+F+G4 model was determined as the best fit substitution model. Phylogenetic reconstructions were first done using the maximum likelihood (ML) method, performed by IQ-Tree that is integrated in the Phylosuite [73] a GUI-based software written in python 3.6.7, and the analyses was run with 1000 bootstrap replicates (Figure S2). Bayesian Inference phylogenies were then inferred using MrBayes 3.2.6 [74] under GTR+G+F model (2 parallel runs, 10,000 generations), in which the initial 25 sampled data were discarded as burn-in (Figure S3). FigTree v1.4.4 was used to visualize and refine the trees. The trees were then combined using AI software (Figure S4).

\section{Conclusions}

Generally, comparative analysis of the structure of the chloroplast genomes of these selected suborder Portulacineae species has revealed several divergences among their genomes. Most species displayed the typical structure of the cp genomes of order Caryophyllales, with a few species revealing some unique features. Generally, R. baccifera and Mammillaria zephyranthoides, seem to have a higher number of rearrangements among these species.

We hereby conclude that $R$. baccifera underwent a larger number of mutational events during its evolution, as evidenced by the large number of rearrangements in its cp genome structure. This might have enabled $R$. baccifera to have a high distribution and be able to survive in different environments. We recommend further cp genome analysis of all subspecies of $R$. baccifera, especially those found outside the New World, to analyze and compare their $\mathrm{cp}$ genome structure and provide more insight on their relationship. 
Supplementary Materials: The following are available online at http://www.mdpi.com/2223-7747/9/8/979/s1, Figure S1: Genome structural alignment of order Caryophyllales species, Figure S2: Phylogenetic analysis of thirty six species order Caryophyllales using maximum likelihood (ML), Figure S3: Phylogenetic analysis of thirty six species order Caryophyllales using Bayesian method, Table S1: Complete chloroplast genomes used in phylogenetic analysis, Table S2: Codon usage in the chloroplast genome of Rhipsalis baccifera, Table S3: Table showing the frequency of repeats and their location in chloroplast genome of Rhipsalis baccifera, Table S4: Table showing the types of SSR repeats found suborder Portulacineae.

Author Contributions: Author Contributions: G.W.-H. and Q.-F.W. designed and supervised the study. M.A.O., J.-X.Y. and X.D. performed the experiment. M.A.O., J.-X.Y., X.D. and V.O.W. performed data analysis. M.A.O. drafted the manuscript. J.-X.Y., X.D., V.O.W., E.M.M., J.N.M., P.C.R. and V.O.O. revised the manuscript. All authors contributed to and approved the final manuscript. All authors have read and agreed to the published version of the manuscript.

Funding: This work was supported by the National Natural Science Foundation of China (31970211) and Sino-Africa Joint Research Center, CAS (SAJC201614).

Acknowledgments: We sincerely thank Geoffrey Mwachala and the entire management team of National Museums of Kenya (NMK), Kenya Forest Service (KFS) and Kenya Wildlife Service (KWS) for making it possible for us to carry out this study by processing the necessary papers. We also thank Robert Wahiti Gituru for his support and supervision during this study. Special thanks go to anonymous reviewers for their insightful and helpful comments and editorial corrections to improve our manuscript.

Conflicts of Interest: The authors declare no conflict of interest.

\section{References}

1. Hershkovitz, M.A.; Zimmer, E.A. On the evolutionary origins of the cacti. Taxon 1997, 46, 217-232. [CrossRef]

2. Nobel, P.S. CactiBiology and Uses; University of California Press: Berkeley, CA, USA; Los Angeles, CA, USA, 2002.

3. Cronquist, A.; Thorne, R.F. Nomenclatural and Taxonomic History. In Caryophyllales; Behnke, H.D., Marby, T.J., Eds.; Springer: Berlin/Heidelberg, Germany, 1994; pp. 5-25.

4. Nyffeler, R. The closest relatives of cacti: Insights from phylogenetic analyses of chloroplast and mitochondrial sequences with special emphasis on relationships in the tribe Anacampseroteae. Am. J. Bot. 2007, 94, 89-101. [CrossRef]

5. Nyffeler, R.; Eggli, U. Disintegrating Portulacaceae: A new familial classification of the suborder Portulacineae (Caryophyllales) based on molecular and morphological data. TAXON 2010, 59, 227-240. [CrossRef]

6. Nyffeler, R.; Eggli, U.; Ogburn, M.; Edwards, E. Variations On A Theme: Repeated Evolution Of Succulent Life Forms In the Portulacineae (Caryophyllales). Haseltonia 2008, 14, 26-36. [CrossRef]

7. Ocampo, G.; Columbus, J.T. Molecular phylogenetics, historical biogeography, and chromosome number evolution of Portulaca (Portulacaceae). Mol. Phylogenetics Evol. 2012, 63, 97-112. [CrossRef] [PubMed]

8. Barthlott, W.; Burstedde, K.; Geffert, J.; Ibisch, P.; Korotkova, N.; Miebach, A.; Rafiqpoor, M.D.; Stein, A.; Mutke, J. Biogeography and Biodiversity of Cacti. Schumannia 2015, 7, 208.

9. Barthlott, W.; Taylor, N.P. Notes towards a Monograph of Rhipsalideae (Cactaceae). Bradleya 1995, 13, 43-79. [CrossRef]

10. Hunt, D.; Taylor, N.; Charles, G. The new cactus lexicon; DH Books: Chapel Hill, NC, USA, 2006.

11. Bomfim-Patrício, J.H.C.-S.M.C. Seed morphology, polyploidy and the evolutionary history of the epiphytic cactus Rhipsalis baccifera (Cactaceae). Polibotanica 2010, 29, 107-129.

12. Barthlott, W. Biogeography and evolution in neo- and palaeotropical Rhipsalinae (Cactaceae). In Proceedings of the Dispersal and Distribution: An International Symposium , Hamburg, Germany, 10-12 June 1982; pp. 241-248.

13. Korotkova, N.; Borsch, T.; Quandt, D.; Taylor, N.P.; Müller, K.F.; Barthlott, W.; Yuan, J.; Wang, B.-S.; Sun, J.; Pan, J.; et al. What does it take to resolve relationships and to identify species with molecular markers? An example from the epiphytic Rhipsalideae (Cactaceae). Am. J. Bot. 2011, 98, 1549-1572. [CrossRef]

14. Facciola, S. Cornucopia II: A Source Book of Edible Plants; Kampong Publications: Vista, CA, USA, 1998.

15. DeFilipps, R.A.; Maina, S.L.; Crepin, J. Medicinal Plants of the Guianas (Guyana, Surinam, French Guiana); National Museum of Natural History (US), Department of Botany: Washington, DC, USA, 2004.

16. Christenhusz, M.J.M.; Chase, M.W. Biogeographical patterns of plants in the Neotropics-Dispersal rather than plate tectonics is most explanatory. Bot. J. Linn. Soc. 2012, 171, 277-286. [CrossRef] 
17. Calvente, A.; Andreata, R.H.P.; Vieira, R.C. Stem anatomy of Rhipsalis (Cactaceae) and its relevance for taxonomy. Plant Syst. Evol. 2008, 276,1-7. [CrossRef]

18. Tan, E.A. The phylogeography and cytogenetics of Rhipsalis baccifera: The cactus that made it to the Old World. Ph.D. Theses, Smith College, Northampton, MA, USA, 2016.

19. Korotkova, N. Phylogeny and Evolution of the Epiphytic Rhipsalideae (Cactaceae). Ph.D. Thesis, University of Bonn, Bonn, Germany, 2011.

20. Ravi, V.; Khurana, J.P.; Tyagi, A.K.; Khurana, P. An update on chloroplast genomes. Plant Syst. Evol. 2007, 271, 101-122. [CrossRef]

21. Burke, S.V.; Grennan, C.P.; Duvall, M.R. Plastome sequences of two New World bamboos-Arundinaria gigantea and Cryptochloa strictiflora (Poaceae)-extend phylogenomic understanding of Bambusoideae. Am. J. Bot. 2012, 99, 1951-1961. [CrossRef]

22. Dong, W.; Xu, C.; Cheng, T.; Zhou, S. Complete Chloroplast Genome of Sedum sarmentosum and Chloroplast Genome Evolution in Saxifragales. PLOS ONE 2013, 8, e77965. [CrossRef]

23. Huang, H.; Shi, C.; Liu, Y.; Mao, S.-Y.; Gao, L.-Z. Thirteen Camellia chloroplast genome sequences determined by high-throughput sequencing: Genome structure and phylogenetic relationships. BMC Evol. Boil. 2014, 14, 151. [CrossRef]

24. Yi, D.-K.; Lee, H.-L.; Sun, B.-Y.; Chung, M.Y.; Kim, K.-J. The Complete Chloroplast DNA Sequence of Eleutherococcus senticosus (Araliaceae); Comparative Evolutionary Analyses with Other Three Asterids. Mol. Cells 2012, 33, 497-508. [CrossRef]

25. Bell, C.D.; Soltis, U.E.; Soltis, P.S. The age and diversification of the angiosperms re-revisited. Am. J. Bot. 2010, 97, 1296-1303. [CrossRef]

26. Drouin, G.; Daoud, H.; Xia, J. Relative rates of synonymous substitutions in the mitochondrial, chloroplast and nuclear genomes of seed plants. Mol. Phylogenetics Evol. 2008, 49, 827-831. [CrossRef] [PubMed]

27. Henry, R.J. Plant Diversity and Evolution: Genotypic and Phenotypic Variation in Higher Plants; CABI Publishing: Wallingford, UK, 2005; 332p. [CrossRef]

28. Wolfe, K.H.; Li, W.-H.; Sharp, P.M. Rates of nucleotide substitution vary greatly among plant mitochondrial, chloroplast, and nuclear DNAs. In Proceedings of the Proceedings of the National Academy of Sciences. Proc. Natl. Acad. Sci. USA 1987, 84, 9054-9058. [CrossRef]

29. Cosner, E.M.; Raubeson, A.L.; Jansen, R.K. Chloroplast DNA rearrangements in Campanulaceae: Phylogenetic utility of highly rearranged genomes. BMC Evol. Boil. 2004, 4, 27. [CrossRef]

30. Solórzano, S.; Chincoya, D.A.; Sanchez-Flores, A.; Estrada, K.; Díaz-Velásquez, C.E.; González-Rodríguez, A.; Vaca-Paniagua, F.; Dávila, P.; Arias, S.; Flores, S.-; et al. De Novo Assembly Discovered Novel Structures in Genome of Plastids and Revealed Divergent Inverted Repeats in Mammillaria (Cactaceae, Caryophyllales). Plants 2019, 8, 392. [CrossRef] [PubMed]

31. Isaac, N.J.B. Taxonomic inflation: Its influence on macroecology and conservation. Trends Ecol. Evol. 2004, 19, 464-469. [CrossRef] [PubMed]

32. Haig, S.M.; Beever, E.A.; Chambers, S.M.; Draheim, H.M.; Dugger, B.D.; Dunham, S.; Elliott-Smith, E.; Fontaine, J.B.; Kesler, D.C.; Knaus, B.J.; et al. Taxonomic Considerations in Listing Subspecies Under the U.S. Endangered Species Act. Conserv. Boil. 2006, 20, 1584-1594. [CrossRef] [PubMed]

33. Liu, X.; Li, Y.; Yang, H.; Zhou, B. Chloroplast Genome of the Folk Medicine and Vegetable Plant Talinum paniculatum (Jacq.) Gaertn.: Gene Organization, Comparative and Phylogenetic Analysis. Molecules 2018, 23, 857. [CrossRef]

34. Jansen, R.K.; Raubeson, L.A.; Boore, J.L.; dePamphilis, C.W.; Chumley, T.W.; Haberle, R.C.; Wyman, S.K.; Alverson, A.J.; Peery, R.; Herman, S.J.; et al. Methods for Obtaining and Analyzing Whole Chloroplast Genome Sequences. In Methods in Enzymology; Academic Press: Cambridge, MA, USA, 2005; Volume 395, pp. 348-384.

35. Li, B.; Zheng, Y. Dynamic evolution and phylogenomic analysis of the chloroplast genome in Schisandraceae. Sci. Rep. 2018, 8, 9285. [CrossRef]

36. Plunkett, G.M.; Downie, S.R. Expansion and Contraction of the Chloroplast Inverted Repeat in Apiaceae Subfamily Apioideae. Syst. Bot. 2000, 25, 648. [CrossRef]

37. McPherson, M.A.; Fay, M.F.; Chase, M.W.; Graham, S.W. Parallel Loss of a Slowly Evolving Intron from Two Closely Related Families in Asparagales. Syst. Bot. 2004, 29, 296-307. [CrossRef] 
38. Jansen, R.K.; Wojciechowski, M.F.; Sanniyasi, E.; Lee, S.-B.; Daniell, H.W. Complete plastid genome sequence of the chickpea (Cicer arietinum) and the phylogenetic distribution of rps12 and clpP intron losses among legumes (Leguminosae). Mol. Phylogenetics Evol. 2008, 48, 1204-1217. [CrossRef]

39. McNeal, J.R.; Kuehl, J.V.; Boore, J.L.; Leebens-Mack, J.; Depamphilis, C.W. Parallel Loss of Plastid Introns and Their Maturase in the Genus Cuscuta. PLOS ONE 2009, 4, e5982. [CrossRef]

40. Liu, X.; Yang, H.; Zhao, J.; Zhou, B.; Li, T.; Xiang, B. The complete chloroplast genome sequence of the folk medicinal and vegetable plant purslane (Portulaca oleracea L.). J. Hortic. Sci. Biotechnol. 2017, 93, 356-365. [CrossRef]

41. Sanderson, M.J.; Copetti, D.; Búrquez, A.; Bustamante, E.; Charboneau, J.L.M.; Eguiarte, L.E.; Kumar, S.; Lee, H.O.; Lee, J.; McMahon, M.; et al. Exceptional reduction of the plastid genome of saguaro cactus (Carnegiea gigantea): Loss of the ndh gene suite and inverted repeat. Am. J. Bot. 2015, 102, 1115-1127. [CrossRef] [PubMed]

42. Liu, S.; Wang, Z.; Wang, H.; Su, Y.; Wang, T. Patterns and Rates of Plastid rps12 Gene Evolution Inferred in a Phylogenetic Context using Plastomic Data of Ferns. Sci. Rep. 2020, 10, 1-12. [CrossRef] [PubMed]

43. Yamaguchi, K.; Subramanian, A.R. Proteomic identification of all plastid-specific ribosomal proteins in higher plant chloroplast 30 S ribosomal subunit. PSRP-2 (U1A-type domains), PSRP-3alpha/beta (ycf65 homologue) and PSRP-4 (Thx homologue). JBIC J. Boil. Inorg. Chem. 2003, 270, 190-205. [CrossRef] [PubMed]

44. Kang, J.-S.; Lee, B.Y.; Kwak, M. The complete chloroplast genome sequences of Lychnis wilfordii and Silene capitata and comparative analyses with other Caryophyllaceae genomes. PLoS ONE 2017, 12, e0172924. [CrossRef] [PubMed]

45. Sloan, D.B.; Triant, D.A.; Forrester, N.J.; Bergner, L.M.; Wu, M.; Taylor, U.R. A recurring syndrome of accelerated plastid genome evolution in the angiosperm tribe Sileneae (Caryophyllaceae). Mol. Phylogenetics Evol. 2014, 72, 82-89. [CrossRef] [PubMed]

46. Kohler, M.; Reginato, M.; Souza-Chies, T.T.; Majure, L.C. Insights into chloroplast genome variation across Opuntioideae (Cactaceae). bioRxiv 2020. [CrossRef]

47. He, Z.; Mi, H. Functional Characterization of the Subunits N, H, J, and O of the NAD(P)H Dehydrogenase Complexes in Synechocystis sp. Strain PCC 6803. Plant Physiol. 2016, 171, 1320-1332. [CrossRef]

48. Downie, S.R.; Palmer, J.D. A Chloroplast DNA Phylogeny of the Caryophyllales Based on Structural and Inverted Repeat Restriction Site Variation. Syst. Bot. 1994, 19, 236. [CrossRef]

49. Salim, H.M.W.; Cavalcanti, A.R.O. Factors influencing codon usage bias in genomes. J. Braz. Chem. Soc. 2008, 19. [CrossRef]

50. Zotov, V.; Punina, N.V.; Dorokhov, D.B.; Schaad, N.W.; Ignatov, A. Phylogenetic Changes in Chloroplast Genomes. Comp. Evol. Genom. Proteom. 2006, 1, 249-252.

51. Sharp, P.M.; Li, W.-H. The codon adaptation index-a measure of directional synonymous codon usage bias, and its potential applications. Nucleic Acids Res. 1987, 15, 1281-1295. [CrossRef] [PubMed]

52. Haberle, R.C.; Fourcade, H.M.; Boore, J.L.; Jansen, R.K. Extensive Rearrangements in the Chloroplast Genome of Trachelium caeruleum are Associated with Repeats and tRNA Genes. J. Mol. Evol. 2008, 66, 350-361. [CrossRef] [PubMed]

53. Vieira, M.L.C.; Santini, L.; Diniz, A.L.; Munhoz, C.D.F. Microsatellite markers: What they mean and why they are so useful. Genet. Mol. Boil. 2016, 39, 312-328. [CrossRef] [PubMed]

54. Lavin, M.; Doyle, J.J.; Palmer, J.D. Evolutionary Significance of the Loss of the Chloroplast-DNA Inverted Repeat in the Leguminosae Subfamily Papilionoideae. Evolution 1990, 44, 390. [CrossRef]

55. Palmer, J.D.; Osorio, B.; Thompson, W.F. Evolutionary significance of inversions in legume chloroplast DNAs. Curr. Genet. 1988, 14, 65-74. [CrossRef]

56. Shinozaki, K.; Ohme, M.; Tanaka, M.; Wakasugi, T.; Hayashida, N.; Matsubayashi, T.; Zaita, N.; Chunwongse, J.; Obokata, J.; Yamaguchi-Shinozaki, K.; et al. The complete nucleotide sequence of the tobacco chloroplast genome: Its gene organization and expression. EMBO J. 1986, 5, 2043-2049. [CrossRef]

57. Schmitz-Linneweber, C.; Williams-Carrier, R.E.; Williams-Voelker, P.M.; Kroeger, T.S.; Vichas, A.; Barkan, A. A Pentatricopeptide Repeat Protein Facilitates the trans-Splicing of the Maize Chloroplast rps12 Pre-mRNA. Plant Cell 2006, 18, 2650-2663. [CrossRef] 
58. Keller, J.; Rousseau-Gueutin, M.; Martin, G.; Morice, J.; Boutte, J.; Coissac, E.; Ourari, M.; Aïnouche, M.; Salmon, A.; Cabello-Hurtado, F.; et al. The evolutionary fate of the chloroplast and nuclear rps16 genes as revealed through the sequencing and comparative analyses of four novel legume chloroplast genomes from Lupinus. DNA Res. 2017, 24, 343-358. [CrossRef]

59. Steyn, E.M.A.; Smith, G. Talinum paniculatum, a naturalized weed in South Africa. Bothalia Afr. Biodiv. Conserv. 2002, 31, 195-197.

60. Veselova, T.; Dzhalilova, K.K.; Remizowa, M.; Timonin, A. Embryology of Talinum paniculatum (Jacq.) Gaertn. and T. triangulare (Jacq.) Willd. (Portulacaceae s.l., Caryophyllales). Wulfenia 2012, 19, 107-129.

61. Doyle, J. DNA protocols for plants. In Molecular Techniques in Taxonomy; Hewitt, G.M., Johnston, A.W.B., Young, J.P.W., Eds.; Springer: Berlin/Heidelberg, Germany, 1991; pp. 283-293.

62. Jin, J.-J.; Yu, W.-B.; Yang, J.-B.; Song, Y.; Depamphilis, C.W.; Yi, T.-S.; Li, D.-Z. GetOrganelle: a fast and versatile toolkit for accurate de novo assembly of organelle genomes. bioRxiv 2018. [CrossRef]

63. Tillich, M.; Lehwark, P.; Pellizzer, T.; Ulbricht-Jones, E.S.; Fischer, A.; Bock, R.; Greiner, S. GeSeq-Versatile and accurate annotation of organelle genomes. Nucleic Acids Res. 2017, 45, W6-W11. [CrossRef] [PubMed]

64. Lowe, T.M.; Chan, P.P. tRNAscan-SE On-line: Integrating search and context for analysis of transfer RNA genes. Nucleic Acids Res. 2016, 44, W54-W57. [CrossRef] [PubMed]

65. Qu, X.-J.; Moore, M.J.; Li, D.-Z.; Yi, T.-S. PGA: A software package for rapid, accurate, and flexible batch annotation of plastomes. Plant Methods 2019, 15, 50. [CrossRef]

66. Lohse, M.; Drechsel, O.; Kahlau, S.; Bock, R. OrganellarGenomeDRAW-A suite of tools for generating physical maps of plastid and mitochondrial genomes and visualizing expression data sets. Nucleic Acids Res. 2013, 41, W575-W581. [CrossRef]

67. Sudhir Kumar, G.S.; Tamura, K. MEGA7: Molecular Evolutionary Genetics Analysis version 7.0. Mol. Biol. Evol. 2013, 30, 2725-2729.

68. Kurtz, S. REPuter: The manifold applications of repeat analysis on a genomic scale. Nucleic Acids Res. 2001, 29, 4633-4642. [CrossRef]

69. Thiel, T.; Michalek, W.; Varshney, R.K.; Graner, A. Exploiting EST databases for the development and characterization of gene-derived SSR-markers in barley (Hordeum vulgare L.). Theor. Appl. Genet. 2003, 106, 411-422. [CrossRef]

70. Frazer, K.A.; Pachter, L.; Poliakov, A.; Rubin, E.M.; Dubchak, I. VISTA: Computational tools for comparative genomics. Nucleic Acids Res. 2004, 32, W273-W279. [CrossRef]

71. Darling, E.A.; Mau, B.; Blattner, F.R.; Perna, N.T. Mauve: Multiple Alignment of Conserved Genomic Sequence with Rearrangements. Genome Res. 2004, 14, 1394-1403. [CrossRef]

72. Kalyaanamoorthy, S.; Minh, B.Q.; Wong, T.; Von Haeseler, A.; Jermiin, L.S. ModelFinder: Fast model selection for accurate phylogenetic estimates. Nat. Methods 2017, 14, 587-589. [CrossRef] [PubMed]

73. Zhang, D.; Gao, F.-L.; Jakovlić, I.; Zou, H.; Zhang, J.; Li, W.X.; Wang, G.T.; Zhou, H. PhyloSuite: An integrated and scalable desktop platform for streamlined molecular sequence data management and evolutionary phylogenetics studies. Mol. Ecol. Resour. 2019, 20, 348-355. [CrossRef] [PubMed]

74. Ronquist, F.; Teslenko, M.; Van Der Mark, P.; Ayres, D.L.; E Darling, A.; Höhna, S.; Larget, B.; Liu, L.; Suchard, M.A.; Huelsenbeck, J.P. MrBayes 3.2: Efficient Bayesian Phylogenetic Inference and Model Choice Across a Large Model Space. Syst. Biol. 2012, 61, 539-542. [CrossRef] [PubMed]

(C) 2020 by the authors. Licensee MDPI, Basel, Switzerland. This article is an open access article distributed under the terms and conditions of the Creative Commons Attribution (CC BY) license (http://creativecommons.org/licenses/by/4.0/). 